\title{
Remittances Sent To and From the Forcibly Displaced
}

\author{
CARLOS VARGAS-SILVA \\ Centre on Migration, Policy and Society, University of Oxford, Oxford, UK
}

\section{Online Appendix}

\section{Key definitions}

Refugee. Term is often used loosely and typically refers to people who are outside their country of origin because they have suffered (or fear) persecution on account of race, religion, nationality, or political opinion; because they are a member of a persecuted social category of persons; or because they are fleeing a war. A legal definition of refugee can also be found in the 1951 United Nations Convention Relating to the Status of Refugees; see UNHCR (2011) for further discussion.

Asylum seeker. omeone who is claiming refugee status, but whose legal claim has not yet been definitively evaluated by the host country. The term 'refugee' is also often used in reference to asylum seekers.

Internally displaced persons (IDPs). Those who are forced to flee their homes for similar reasons as a refugee but who remain within the borders of their home country.

Displaced person. For the purposes of this article, a person who is a refugee, asylum seeker, or IDP. Note that, in general, forced migration is a broader term that not only encompasses people fleeing persecution or conflict, but also those escaping environmental change or natural or human-made disasters or migrating because of development projects.

Protracted displacement. Refers to long-term displacement without an end in sight. Often defined in policy circles as a situation in which 25,000 or more refugees originating from the same country have sought asylum in another country for at least five consecutive years; see UNHCR (2004) for further discussion.

First country of asylum. Refers to the neighbouring country to which refugees flee originally.

Third country of asylum. Refers to the next country of residence after the first country of asylum. The concepts of first and third country of asylum also have legal implications for asylum applications; see Legomsky (2003) for further discussion.

\section{Methodology}

Different sources were explored by searching the key term 'remittances'. If too many hits appeared, then the search was limited to the following terms:

\begin{tabular}{|lll|}
\hline$\bullet \quad$ 'remittances' and 'refugees' & $\bullet$ & 'remittances' and 'forced migrants' \\
$\bullet \quad$ 'remittances' and 'IDPs' & $\bullet$ & 'remittances' and 'conflict' \\
$\bullet \quad$ 'remittances' and 'displacement' & $\bullet \quad$ 'remittances' and 'violence' \\
\hline
\end{tabular}


For academic pieces the following databases were explored:

\begin{tabular}{|ll|}
\hline - Google Scholar & $\bullet$ RePec \\
- JSTOR & $\bullet$ EconLit \\
\hline
\end{tabular}

To make sure that recent material (particularly working papers) was included, the websites of the following academic centres were searched:

- Centre for Research and Analysis of Migration, University College London

- Centre on Migration, Policy and Society, Oxford

- International Migration Institute, Oxford

- Sussex Centre for Migration Research

- Center for Migration and Development, Princeton

- Maastricht Centre for Citizenship, Migration and Development

- Migration Research Center, Turkey

- Institute for the Study of International Migration, United States

- Stockholm International Peace Research Institute
- Refugee Studies Centre, Oxford

- Institute for the Study of Labor (IZA), Bonn

- International Growth Centre, London School of Economics

- Center for Comparative Immigration Studies, University of California-San Diego

- London School of Economics Migration Studies Unit

- Center for Migration and Refugee Studies, Cairo

- Households in Conflict Network

- Peace Research Institute, Oslo

The websites of the following organisations were visited to include policy-related material:

- Asian Development Bank

- European Commission

- Center for Global Development

- UK Department for International Development

- GIZ

- International Fund for Agricultural Development

- Inter-American Dialogue

- Internal Displacement Monitoring Centre

- Canada's International Development Research Centre

- Institute for Development Studies

- Inter-American Development Bank
- International Organization for Migration

- Institute of Public Policy Research

- Migration Policy Institute

- Overseas Development Institute

- Organisation for Economic Co-operation and Development

- Oxfam

- Pew Research Center

- Other UN websites (including UNHCR, UNU-WIDER, and others)

- World Bank

- US Agency for International Development 
Relevant unpublished material was included by searching the programmes of related conferences held during the last few years, including the following:

- International Conference on Migration and Development, World Bank

- Annual Migration Meeting, Institute for the Study of Labor

- Metropolis
- NORFACE Research Program on Migration conferences

- IMISCOE (International Migration, Integration, and Social Cohesion) conferences

- International Association for the Study of Forced Migration

\section{Methodological considerations for new quantitative research}

3.1. Existing data sets. To conduct quantitative research on remittances to and from the displaced, it is necessary to identify the sender or receiver of remittances as a displaced person. Ways in which to make this identification depend on the context. Possibilities include surveys that only look at displaced persons or contain information related to place of birth and reason for movement. The discussion below includes examples of the types of surveys that could be used to explore remittances in situations of forced displacement.

3.1.1. Surveys of the forcibly displaced. Some surveys focus exclusively on forced displacement. In these surveys, all respondents are part of the target group. The only additional requirement is for the survey to request information on remittances (sent or received). Unfortunately, many of these surveys are not publicly available for researchers to use.

3.1.2. General surveys in which it is possible to identify the displaced. Surveys that target a representative sample of a certain population (for example, nationally representative, representative of the whole migrant population, representative of the migrant population from certain countries) often include a way to directly identify the displaced. These surveys provide the best opportunity for empirical research because comparisons can be made between the displaced and other groups, such as economic migrants or non-migrants, and data sets are often easily accessed by researchers.

Most of these surveys record the movement history of respondents. If a person is defined as a 'migrant', a follow-up question about reasons for migration is often included. Typically this follow-up question will include whether the main reason (or one of the main reasons) for migration was escaping conflict, war, violence, repression, or persecution; increasing security or safety; or for political or religious discrimination or claiming asylum or becoming a refugee. The actual wording of the question differs across surveys, but in general, responses can be used to broadly identify those who are displaced.

3.2. Additional quantitative data collection. This section discusses some content and methodological considerations for future quantitative surveys exploring remittances in the displacement context. These recommendations are based on the findings from the literature review. This is not intended to be a full explanation of the issues. Several studies discuss data collection in the forced migration context (Jacobsen and Landau, 2003) and methodological considerations for remittances surveys in general (Brown et al., 2014).

3.2.1. Control group. One of the limitations of many existing surveys with relatively large samples of displaced is that there is no control group (Jacobsen and Landau, 2003). These surveys often only include the forcibly displaced, which makes it impossible to directly explore whether the displaced differ substantially from non-migrants or from economic migrants. New surveys should aim to include a control group. The nature of the control group will differ with the purpose of the 
study. Sometimes the control group might refer to a sample of the host population living close to the displaced; in other cases it could be those from the same location of origin who remained home. The important issue is for surveys to allow some kind of comparison with those who are not displaced.

3.2.2. Longitudinal data. Another limitation of many existing surveys is that they have no longitudinal component. Therefore, the medium- and long-term impacts on displaced populations of receiving remittances cannot be explored. Previous studies have provided insights into the long-term impacts of remittances in the post-conflict setting, such as the possibility of further migration abroad (Dimova and Wolff, 2015). Longitudinal information is necessary for these dynamics to be studied in detail.

3.2.3. Multiple destinations and sources. On the sending side, the evidence suggests that remittances from the displaced often go to several destinations (regions or countries). Therefore, it is important for surveys to collect information on the money's different destinations, including different regions within the same country. The evidence also suggests that refugees often send money to other refugees and to IDPs. Therefore, it is also important to note whether any of the recipients of the money are or have been forcibly displaced.

On the receiving side, the evidence review also suggests that displaced persons receive money from different countries, including the conflict-affected home country. If a person or household receives money from different people, it is important for surveys to collect information on the different senders. It would be particularly useful to know whether any of the senders are also displaced.

3.2.4. Underreporting. Researchers are in general agreement that respondents underreport receiving remittances or underreport the amount of money received (Brown et al., 2014). Many displaced persons receive assistance from government authorities, and reporting remittances might affect their eligibility for assistance. Also, security could be an issue and reporting remittances might be associated by some interviewees with greater exposure to theft. Finally, political or legal issues could surround sending or receiving remittances. Sending remittances might be seen as indirect support for the home country or region government, and receiving remittances can be seen as attachment to diaspora groups opposed to the government. In fact, in some historical cases sending remittances to the home country has been explicitly prohibited by the host country (for example, remittances to Cuba from the United States).

The problem of underreporting could be addressed by asking about remittances in different ways to allow for comparison of answers (for example, total amount, share of income, share of expenditures). Also, Brown et al. (2014) suggest that in settings with strong social pressure to remit, questions could be presented in ways that ultimately excuse non-remitting. Finally, it is possible to triangulate information from different research methods, including discussion groups.

3.2.5. Pre-conflict information. Many surveys contain information on the situation of displaced and migrant households before migration. This information is used to control for previous characteristics, such as wealth. In those situations, in which displacement is clearly the result of conflict with a defined start date, it would be useful to gather information on the pre-conflict situation. This information would provide a better control for background of the household given that the household's pre-movement situation could have already been seriously affected by conflict.

3.2.6. Multiple recipients. Many of the existing studies suggest that remittances sent to the displaced are often received by a single person who then distributes the money to other people. Surveys need to take this into account and make sure to differentiate between the receiver of the money and the person for whom the money is intended. Also, it is important to understand who is in charge of determining the overall distribution of the money (that is, the sender or the person distributing the money). 


\section{References}

Brown, R. P. C., Carling, J., Fransen, S., \& Siegel, M. (2014). Measuring remittances through surveys: Methodological and conceptual issues for survey designers and data analysts. Demographic Research, 31(41), 1243-1274. doi:10.4054/ DemRes.2014.31.41

Dimova, R. \& Wolff, F. (2015). Remittances and chain migration: Longitudinal evidence from Bosnia and Herzegovina. Journal of Development Studies, 51(5), 554-568.

Jacobsen, K. \& Landau, L. (2003). The dual imperative in refugee research: Some methodological and ethical considerations in social science research on forced migration. Disasters, 27(3), 185-206.

Legomsky, S. H. (2003). Secondary refugee movements and the return of asylum seekers to third countries: The meaning of effective protection. International Journal of Refugee Law, 15(4), 567-677.

United Nations High Commissioner for Refugees. (2004). Protracted refugee situations: The search for practical solutions. UNHCR: Geneva.

United Nations High Commissioner for Refugees. (2011). Convention and protocol relating to the status of refugees. UNHCR: Geneva. 